\title{
Long-Term Mechanical Ventilation Equipment for Neuromuscular Patients: Meeting the Expectations of Patients and Prescribers
}

\author{
Frédéric Lofaso MD PhD, Hélène Prigent MD PhD, Vincent Tiffreau MD, \\ Nathalie Menoury MD, Michel Toussaint PT PhD, Armelle Finet Monnier MD, \\ Natalie Stremler MD, Christian Devaux PT, Karl Leroux, David Orlikowski MD PhD, \\ Cécile Mauri MD, Isabelle Pin MD, Sabrina Sacconi MD, Cécile Pereira MD, \\ Jean-Louis Pépin MD PhD, and Brigitte Fauroux MD PhD, for the \\ Association Française Contre les Myopathies research group
}

\begin{abstract}
BACKGROUND: To maximize the likelihood of successful long-term mechanical ventilation (MV) in patients with neuromuscular diseases, ventilator characteristics and settings must be chosen carefully, taking into account both medical requisites and the patient's preference and comfort. OBJECTIVES: To evaluate patients' knowledge about and comfort with their long-term MV; to compare patients' and prescribers' opinions and expectations regarding long-term MV; and to compare the equipment used by the patients to the prescribers' current MV prescription. METHODS: Neuromuscular patients receiving long-term MV, and home MV prescribers in Belgium and France were asked to respond to a questionnaire survey specifically developed for the study. RESULTS: Completed questionnaires were collected from 209 patients (mean age 35.4 $\pm 15.9 \mathrm{y}$, range 3-86 y), ventilated since $11 \pm 17$ year, and $45 \mathrm{MV}$ prescribers. One hundred sixty-three $(\mathbf{7 8 \%})$ patients correctly designated their MV mode as a volume or pressure controlled mode. When an inspiratory trigger was available, $92 \%$ of the patients were able to use it, but only $69 \%$ were satisfied. Prescribers were more prone than patients to use new technologies such as an emergency-release system for the noninvasive interface (1-10 visual analog scale score $9.2 \pm 1.5$ vs $6.8 \pm 3.3, P<.001)$, a humidification system $(8.6 \pm 1.4$ vs $7.8 \pm 2.6, P=.02)$, a contactor for providing larger inspiratory volumes $(8.4 \pm 1.7$ vs $6.0 \pm 3.0, P=.009)$, a built-in cough assistance mode $(9.2 \pm 1.4$ vs $5.5 \pm 3.5, P<.001)$, new options to improve speech, or new MV modes such as a volume-targeted pressure control. CONCLUSIONS: The opinions of patients and prescribers differed about the ideal home ventilator. Patients were less prone to use new technologies, mainly because of a lack of information, underlining the need for regular MV update in patients receiving long-term MV. Key words: home care; masks; mouthpieces; myopathies; patient-centered care; respiratory failure. [Respir Care 2014;59(1):97-106. @ 2014 Daedalus Enterprises]
\end{abstract}

\section{Introduction}

Clinical outcomes of neuromuscular patients using longterm mechanical ventilation (MV) depend not only on med-

Drs Lofaso, Prigent, and Orlikowski are affiliated with PhysiologieExplorations Fonctionnelles, et Le Centre d'Investigation Clinique et d'Innovation Technologique Unité Mixte de Recherche 805, Hôpital Raymond Poincaré, Assistance Publique Hôpitaux de Paris, Garches, France. Dr Tiffreau is affiliated with Centre de Référence des Maladies Neuromusculaires, Centre Hospitalier Régional Universitaire, Lille, France. Dr Menoury is affiliated with Maison d'Accueil Spécialisée Yolaine ical factors, but also on MV equipment and the quality of the home support. ${ }^{1,2}$ Selecting the best MV equipment and

de Kepper, Saint-Georges-sur-Loire, France. Dr Toussaint is affiliated with the Centre for Home Mechanical Ventilation, Inkendaal Rehabilitation Hospital, Brussels, Belgium. Drs Finet Monnier and Stremler are affiliated with the Centre de Référence des Maladies Neuromusculaires, Centre Hospitalier Universitaire Timone, Assistance Publique Hôpitaux de Marseille, Marseille, France. Mr Devaux is affiliated with the Département des Actions Médicales, Association Française Contre les Myopathies, Evry, France. Mr Leroux is affiliated with l'Association d'Entraide des Polios et Handicapés Assistance, Suresnes, France. 
the optimal settings for each patient is crucial for the success of long-term MV.

Although patient comfort is widely recognized as a crucial determinant of MV adherence and efficacy, ${ }^{3}$ few studies have evaluated patients' opinions concerning MV equipment. Patient comfort is affected by many factors, including patient-ventilator synchrony, ventilator inability to cope with the patient's respiratory demand, skin lesions caused by the interface, inappropriate humidification, and difficulty speaking during MV. Patients receiving long-term MV at home are expected to have an "expert" opinion on MV because they have been using MV for years in various daily life conditions. Moreover, comparison of the patient's and the prescriber's opinions may be valuable for deciding which technological issues deserve priority. This is of particular interest for neuromuscular patients, as they form the largest home-MV population ${ }^{4}$ and use either noninvasive ventilation (NIV) or invasive MV via tracheos-

Dr Mauri is affiliated with l'Association Pour l'Insertion des Grands Handicapés Respiratoires Et Moteurs, St-Mathieu-de-Tréviers, France. Drs Pin and Pépin are affiliated with Pôle Couple Enfants et Pôle Locomotion, Rééducation et Physiologie, Centre Hospitalier Universitaire de Grenoble, Grenoble, France. Drs Sacconi and Pépin are affiliated with the Centre de Référence Maladies Neuromusculaires/Sclérose Latérale Amyotrophique, Hôpital Archet 1, Centre Hospitalier Universitaire de Nice, Nice, France. Drs Pereira and Pépin are affiliated with the Centre de Compétences-Pneumologie Maladie Neuromusculaire, Centre Hospitalier Universitaire de Nice, Nice, France. Dr Pépin is also affiliated with the Institut National de la Santé et de la Recherche Médicale U 1042, HP2 Laboratory, Université Joseph Fourier, Faculté de Médecine, Grenoble, France. Dr Fauroux is affiliated with the Centre de Référence des Maladies Respiratoires Rares, Pneumologie Pédiatrique et Institut National de la Santé et de la Recherche Médicale U 955, Université Pierre et Marie Curie-Paris 6, Assistance Publique Hôpitaux de Paris, Hôpital Armand Trousseau, Paris, France. Dr Lofaso is also affiliated with the Institut National de la Santé et de la Recherche Médicale U 955, Equipe Biomécanique Cellulaire et Respiratoire, Créteil, France.

ResMed, which manufactures ventilators, was selected by the board of the research group after an industrial application, and participated in the study design and data collection, but had no role in the data analysis (except as described below), the interpretation of the results, the writing of the manuscript, or the decision to submit the paper for publication. Le Centre d'Investigation Clinique et d'Innovation Technologique received $€ 7,000$ from ResMed to pay Isabelle Vaugier for statistical analysis. The authors have disclosed no other conflicts of interest.

Supplementary material related to this paper is available at http:// www.rcjournal.com.

Correspondence: Frédéric Lofaso MD PhD, Services de Physiologie/ Explorations Fonctionnelles, Réanimation Médicale, Rééducation Fonctionnelle et Centre d'Investigation Clinique et d'Innovation Technologique, Institut National de la Santé et de la Recherche Médicale Unit 805, Assistance Publique Hôpitaux de Paris, Hôpital Raymond Poincaré, 92380 Garches, France. E-mail: f.lofaso@rpc.aphp.fr.

DOI: $10.4187 /$ respcare.02229

\section{QUICK LOOK}

\section{Current knowledge}

Patient comfort with, adherence to, and acceptance of, home mechanical ventilation requires appropriate patient education, appropriate clinical prescription, and carefully chosen devices. Patient understanding and acceptance of the ventilator are crucial to the success of home ventilator support.

\section{What this paper contributes to our knowledge}

Clinicians are more likely to prescribe new home ventilation technologies and adjuncts, which are often unproven, than patients are willing to accept those technologies. Clinicians should include patient preferences and provide adequate education when prescribing home ventilation devices and methods.

tomy, ${ }^{1}$ at night and/or during the day, ${ }^{1}$ which may require different interfaces and ventilator modes.

The general objectives of the present survey were: to evaluate patients' knowledge about and comfort with their long-term MV; to compare patients' and prescribers' opinions and expectations regarding long-term $\mathrm{MV}$; and to compare the equipment used by the patients to the prescribers' current MV prescription.

\section{Methods}

This study was approved by the French Commission Nationale de l'Informatique et des Libertés, in agreement with French regulation.

\section{Study Questionnaires}

Data were collected via questionnaires specifically developed for the study, by a scientific committee composed of adult and pediatric teaching-hospital home MV prescribers from Hôpital Raymond Poincaré and Hôpital Armand Trousseau; researchers in respiratory physiology, mechanical properties of the respiratory system, and ventilator development and evaluation from Institut National de la Santé et de la Recherche Médicale [INSERM] 955, team 13; MV home care professionals from l'Association d'Entraide des Polios et Handicapés Assistance, a nonprofit organization supported by Air Liquide; MV physiotherapists; representatives of Association Française Contre les Myopathies, a neuromuscular patient-support organization; and a representative of ResMed, a company that manufactures ventilators, selected by the scientific board after an industrial application. The patient and pre- 
scriber questionnaires were tested prior to finalization by 20 representative neuromuscular patients and 5 home MV prescribers in teaching hospitals in the Paris conurbation, respectively. The patients' ability to understand the questions was checked, as well as the time required to complete the questionnaire, which should be less than $90 \mathrm{~min}$ for both patients and prescribers. The patient questionnaire requested the patient's opinion on long-term MV objectives and potential innovations. The prescriber questionnaire was similar to the patient questionnaire, and requested the prescriber's opinion on home MV objectives and potential innovations. Special care was taken to formulate similar questions in both questionnaires (see the supplementary materials at http://www.rcjournal.com).

The final patient questionnaires were completed by healthcare professionals, between September 2010 and July 2011. If the patient was an adult, the healthcare professional explained all the definitions (eg, synchronization, effectiveness, comfort of ventilation) to improve the understanding of the questions. If the patient was a child, the interview was performed with the parents, who assisted the interviewer to improve the understanding of the questions.

\section{Patient and Prescriber Recruitment}

The objective was to include at least 200 patients, with an equal distribution between patients treated with nocturnal NIV only, patients treated with NIV both night and day, and patients treated with invasive MV via tracheostomy. Patients were recruited at reference medical centers for neuromuscular diseases in Belgium (Inkendaal) and France (Lille, Grenoble, Marseille, Nice, Paris, and Garches) and at residential facilities for neuromuscular patients in France (Evry, Montpellier, and Angers). The criteria for patient inclusion were a diagnosis of neuromuscular disorder, MV for at least 1 year, and the willingness and availability to participate to the study (an interview of $90 \mathrm{~min}$ ). The scientific committee decided not to include patients with amyotrophic lateral sclerosis, due to the rapid progression of this disease.

The objective was to include at least 40 prescribers. The prescribers were selected at random from the address book of Association Française Contre les Myopathies, from which all 89 prescribers were contacted via e-mail, between July 2010 and December 2010, to assess their willingness to participate in the survey. Forty-six prescribers agreed to participate, one refused, and the others did not respond. The questionnaire was sent only to prescribers who agreed to participate. One prescriber did not fill in the questionnaire.

\section{Statistics}

Quantitative parameters are described as mean \pm SD or median and IQR, depending upon the normality of distribution. Qualitative parameters are described as number and percentage. Responses to items present in both the patient and the prescriber questionnaire, particularly those answered via visual analog scale, were compared with the Mann-Whitney test for non-normally distributed variables and the chi-square test or Fisher exact test, as appropriate. Two-sided $P$ values $<.05$ were considered significant. All analyses were performed with statistics software (R, R Foundation, Vienna, Austria).

\section{Results}

\section{Patient and Prescriber Characteristics}

Completed questionnaires were collected from 209 neuromuscular patients. Only 11 patients refused to answer the questionnaire. The patients' mean age was $35.4 \pm 15.9$ years (range 3-86 years), and the mean duration of MV prior to the study was $11 \pm 17$ years. The types of neuromuscular disease and degree of autonomy are reported in Table 1. The ventilators used by the patients are presented in Table 2. Nocturnal NIV was used by 71 patients, and night-and-day NIV by 71 other patients, including 30 patients who used mouth-piece NIV. The remaining 67 (32\%) patients had tracheostomy; among them 6 patients were not ventilated during the daytime.

Completed questionnaires were obtained from 45 prescribers ( 23 pulmonologists, 12 pediatricians, and 10 intensive care specialists), of whom 41 worked in public hospitals. Fifteen prescribers were providers of the patients included in the study. Experience with long-term MV was $>5$ years in 37 prescribers, 5-10 years in 11 prescribers, and $>10$ years in 26 prescribers.

\section{Knowledge and Patient Comfort}

Of the 209 patients, $163(78 \%)$ correctly designated their ventilatory mode as volume controlled, pressure controlled, or pressure-regulated volume control (PRVC), but only $82(39 \%)$ patients knew whether their mode was "assisted," "controlled," or "assist-controlled."

One hundred fifty-eight (76\%) patients found their MV "comfortable" in terms of respiratory sensation (56 [84\%] of those on invasive MV, 56 [79\%] of those on night-andday NIV, and 46 [65\%] of those on nocturnal NIV), and 22 (11\%) patients found their MV "uncomfortable" (12 of those on nocturnal NIV, 8 of those on night-and-day NIV, and 2 of those on invasive MV). Twenty-nine 29 (14\%) patients had no opinion. 
Table 1. Patient Characteristics and Degree of Autonomy

\begin{tabular}{lc}
\hline \hline & \\
& Patients \\
\cline { 2 - 2 } & no. $(\%)$ \\
\hline Female & $69(33)$ \\
Age $\leq 16$ y & $24(11)$ \\
Institutionalized & $40(19)$ \\
Type of neuromuscular disease & \\
Duchenne and Becker muscular dystrophies & $71(35.7)$ \\
Myotonic dystrophies & $35(17.6)$ \\
Spinal muscular atrophies & $20(10.1)$ \\
Congenital myopathies & $15(7.5)$ \\
Sarcoglycanopathies & $8(4.0)$ \\
Proximal myopathies & $6(3.0)$ \\
Other myopathies & $8(4.0)$ \\
Other neuropathies & $30(15.1)$ \\
Degree of autonomy & \\
Able to wash him or herself without help & $47(22.5)$ \\
Needs help washing & $55(26.3)$ \\
Washed by another person & $107(51.2)$ \\
Able to eat without help & $73(35.6)$ \\
Needs help eating & $113(55.1)$ \\
Fed via tube & $19(9.3)$ \\
Able to stand without help & $43(21.3)$ \\
Able to stand with help & $115(56.9)$ \\
Unable to stand & $44(21.8)$ \\
Able to walk without help & $39(19.8)$ \\
Able to walk with help & $27(13.7)$ \\
Cannot walk & $143(68.4)$ \\
Uses a manual wheelchair & $48(24.4)$ \\
Able to drive a car & $19(9.5)$ \\
Drives a power wheelchair & $145(72.5)$ \\
No mobility without help & $36(18)$ \\
\hline &
\end{tabular}

Table 3 describes the patients' reports concerning the ability to use the assisted function and its usefulness. The majority of the patients were able to trigger the ventilator and were satisfied with its sensitivity.

Among the 134 patients (73 on NIV and 61 on invasive MV) who needed daytime ventilation, 73 (54\%) patients (including 13 [9\%] tracheostomized patients) were able to breathe spontaneously. Of the 60 daytime-NIV patients able to breathe spontaneously, $39(65 \%)$ reported feeling better with daytime ventilation: decreased daytime fatigue in $37(62 \%)$, improved eating in $7(12 \%)$, and/or improved speech in $13(22 \%)$. Of the 13 tracheotomized patients able to breathe spontaneously, $11(85 \%)$ reported feeling better with daytime ventilation: decreased daytime fatigue in $10(77 \%)$, improved eating in 7 (54\%), and/or improved speech in $6(46 \%)$.

\section{Comparison of Patient and Prescriber Opinions}

With regard to ventilator performance, except for ventilator efficiency (defined for the patients as the correction
Table 2. Ventilators Used by the Patients

\begin{tabular}{llr}
\hline \hline \multicolumn{1}{c}{ Ventilator } & Manufacturer & $\begin{array}{c}\text { Patients } \\
(\text { no. })\end{array}$ \\
\hline Eole 3 & ResMed & 67 \\
Elisée 150 & ResMed & 32 \\
VIPAP III & ResMed & 6 \\
VIPAP IV & ResMed & 14 \\
VS Integra & ResMed & 1 \\
VS Ultra & ResMed & 8 \\
LegendAir & Covidien & 28 \\
Airox SmartAir & Covidien & 4 \\
Airox Home 2 & Covidien & 1 \\
PB560 & Covidien & 3 \\
Vivo 40 & Breas Medical & 8 \\
Vivo 50 & Breas Medical & 1 \\
Trilogy 100 & Respironics & 9 \\
BiPAP Synchrony & Respironics & 26 \\
BiPAP Harmony & Respironics & 1 \\
\hline
\end{tabular}

of abnormal blood gas values ${ }^{5}$ ) at the expense of comfort, all the ventilator characteristics were considered more important by the prescribers than by the patients (Table 4). Allowing the patient to adjust the ventilatory settings was ranked as a low priority by prescribers and patients, but the prescribers' ranking was higher than the patients' ranking. Both patients and prescribers considered assisted-cough mode an important option, but this importance was also ranked higher by the prescribers than by the patients (see Table 4).

When the patients were asked if they would accept the implantation of 2 electromyography electrodes by means of a minor surgical procedure performed under local anesthesia, in order to improve the synchronization of the ventilator to the patient's inspiratory effort, only 24 (11\%) patients, including 8 nocturnal NIV (11\%), 7 night-andday NIV (10\%), and $9(13 \%)$ tracheostomized patients, agreed immediately; 58 (28\%), including 16 night-and-day NIV, 20 nocturnal NIV, and $22(11 \%)$ tracheostomized patients, answered that they would eventually accept; and 112 (54\%) patients refused, including 39 (55\%) nocturnal NIV, 42 (59\%) night-and-day NIV, and 31(15\%) tracheostomized patients. The remaining patients gave no opinion. The prescribers' mean \pm SD visual analog scale responses concerning the potential interest of this technology (from not useful $=0$ to very useful $=10$ ) was $7.4 \pm 2.3$.

Regarding secretion clearance, $35(17 \%)$ patients, including 7 (10\%) nocturnal NIV, 15 (21\%) night-and-day NIV, and $13(19 \%)$ tracheostomized patients, preferred a mechanical insufflation-exsufflation system; 30 (14\%), including 17 (24\%) nocturnal NIV, 9 (13\%) night-and-day NIV, and $4(6 \%)$ tracheostomized patients, preferred an intermittent inspiratory pressure; and 19 (9\%), including 3 (4\%) nocturnal NIV, 9 (13\%) night-and-day NIV, and 7 
Table 3. Patient Reports Concerning the Inspiratory Trigger

\begin{tabular}{|c|c|c|c|}
\hline & $\begin{array}{c}\text { Nighttime } \\
\text { NIV } \\
(n=60)\end{array}$ & $\begin{array}{c}\text { Night-and-Day } \\
\text { NIV } \\
(n=56)\end{array}$ & $\begin{array}{c}\text { Invasive MV via } \\
\text { Tracheostomy } \\
(n=38)\end{array}$ \\
\hline Ability to use the assisted mode & 58 & 50 & 33 \\
\hline The inspiratory trigger is (too/satisfactory/insufficiently) sensitive & $3 / 41 / 6$ & $2 / 39 / 3$ & $1 / 27 / 6$ \\
\hline \multicolumn{4}{|c|}{ When do you increase the respiratory frequency during mechanical ventilation? } \\
\hline When seeking more air & 19 & 16 & 14 \\
\hline During daily activity like eating or having bowel movement & 3 & 7 & 7 \\
\hline For speaking & 4 & 5 & 4 \\
\hline
\end{tabular}

Table 4. Visual Analogue Scale Scores* for Ventilator Performance, Noninvasive Interface, Humidification and Heating, and Mouthpiece Condition

\begin{tabular}{|c|c|c|c|}
\hline & Patients & Prescribers & $P$ \\
\hline \multicolumn{4}{|l|}{ Ventilator performance } \\
\hline Patient/ventilator synchronization & $8.3 \pm 1.8$ & $9.0 \pm 1.6$ & .01 \\
\hline Greater effectiveness at the expense of decreased comfort & $7.9 \pm 2.0$ & $6.5 \pm 2.2$ & $<.001$ \\
\hline Greater comfort at the expense of decreased effectiveness & $7.5 \pm 2.3$ & $7.9 \pm 1.9$ & .64 \\
\hline Patient able to adjust the settings according to needs & $3.6 \pm 3.7 \dagger$ & $5.5 \pm 2.8$ & $<.001$ \\
\hline Cough support system built into the ventilator & $5.5 \pm 3.5$ & $9.2 \pm 1.4$ & $<.001$ \\
\hline Cough support system built into the ventilator and under patient control & $8.0 \pm 2.8$ & $9.3 \pm 1.2$ & $<.001$ \\
\hline Contactor for providing larger inspiratory volumes for coughing & $6.0 \pm 3.0$ & $8.4 \pm 1.7$ & .009 \\
\hline \multicolumn{4}{|l|}{ Noninvasive interface, $n=142$} \\
\hline Good tolerance of the interface & $9.3 \pm 1.1$ & $9.8 \pm 0.5$ & $<.001$ \\
\hline Satisfactory system for holding the interface in place & $8.9 \pm 1.6$ & $9.6 \pm 0.7$ & $<.001$ \\
\hline Two different interfaces, to alternate pressure points & $6.8 \pm 3.5$ & $9.2 \pm 1.1$ & $<.001$ \\
\hline Ability to independently secure the interface & $8.2 \pm 2.5$ & $8.2 \pm 1.9$ & .69 \\
\hline Ability to independently remove the interface & $8.8 \pm 1.9$ & $9.0 \pm 1.3$ & .95 \\
\hline Emergency release system built into the interface & $6.8 \pm 3.3$ & $9.2 \pm 1.5$ & $<.001$ \\
\hline \multicolumn{4}{|l|}{ Humidification and heating } \\
\hline Humidification system & $7.8 \pm 2.6$ & $8.6 \pm 1.4$ & .02 \\
\hline Heating of the ventilator circuit & $6.7 \pm 3.0$ & $6.9 \pm 2.3$ & .82 \\
\hline \multicolumn{4}{|l|}{ Mouthpiece, $n=30$} \\
\hline Contactor for triggering/stopping insufflation & $4.2 \pm 4.1$ & $7.1 \pm 2.4$ & .02 \\
\hline Off contactor for extending battery life & $7.0 \pm 4.1$ & $7.7 \pm 2.2$ & .55 \\
\hline \multicolumn{4}{|c|}{$\begin{array}{l}\text { Values are mean } \pm \text { SD. } \\
\text { * Visual analog scale: } 0=\text { not important, } 10=\text { very important. } \\
\dagger \text { Between the } 3 \text { groups of patients the only item with a significant difference was "Patient able to adjust the settings according to needs," which was higher in tracheotomized patients (4.4 } \pm 3.7) \\
\text { than in nighttime NIV patients }(2.7 \pm 3.3)(P=.008)\end{array}$} \\
\hline
\end{tabular}

(10\%) tracheostomized patients, preferred a percussive system. The remaining $125(60 \%)$ patients gave no opinion. Among the prescribers, $30(66 \%)$ preferred insufflationexsufflation, $5(11 \%)$ an air-stacking method, $4(9 \%)$ an intermittent inspiratory pressure, and $3(7 \%)$ a percussive system. Two prescribers had no preference.

Table 4 shows that the prescribers were generally more concerned than the patients about tolerance of the interface, the importance of satisfactory headgear, and the possibility of alternating different interfaces to change the pressure points. Although the prescribers were more concerned than the patients about having an emergency interface-release system to allow the patient to release the interface by him or herself, $88(62 \%)$ of the 142 NIV patients were not able to release the interface by themselves.

Humidification of the circuit was considered more important by the prescribers than by the patients, while the importance of heating the circuit was ranked similarly by the patients and the prescribers (see Table 4). 


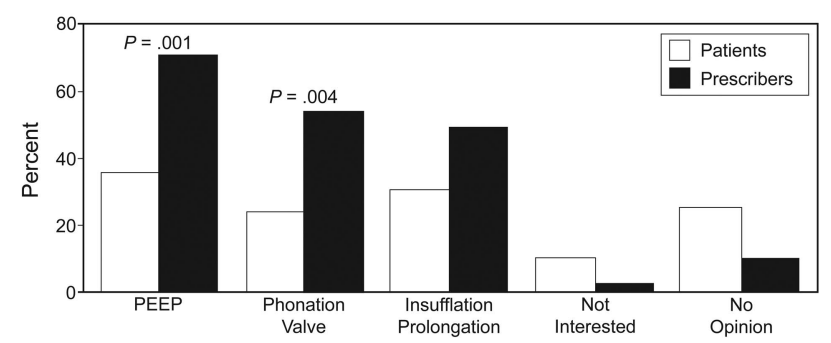

Fig. 1. Proportions of tracheotomized patients and prescribers prepared to use currently available solutions for improving speech in tracheotomized patients.

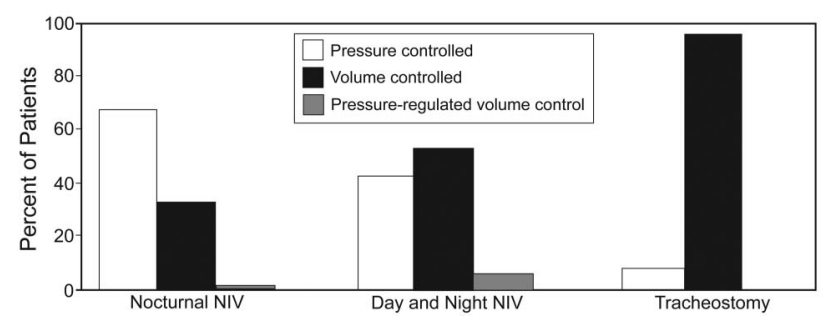

Fig. 2. Distribution of ventilation modes in patients on long-term nocturnal noninvasive ventilation (NIV), patients on day-and-night NIV, and tracheostomized patients.
Concerning mouthpiece ventilation, the prescribers were more eager than patients to have a patient-controlled contactor for triggering/stopping insufflation, in order to meet the patient's needs (see Table 4).

Among the 67 tracheotomized patients, 5 (7\%) used a phonation valve during ventilation. Of the 34 tracheotomized patients able to breathe spontaneously, 15 (44\%) used a phonation valve, $11(32 \%)$ closed their tracheostomy tube completely, and 8 kept their tracheotomy tube open during speech.

Figure 1 reports the 67 tracheotomized patients' and prescribers' opinions about technical changes aimed at improving speech. The prescribers were more eager than the patients to develop technical innovations to improve speech for these patients.

\section{Evaluation of the Patients' Equipment Versus the Prescribers' Equipment Choices}

One hundred twenty-two (59\%) patients were using a volume control mode, $82(39 \%)$ patients were using a pressure control mode, and 5 (2\%) patients were using a PRVC mode. The number of patients using volume control in-

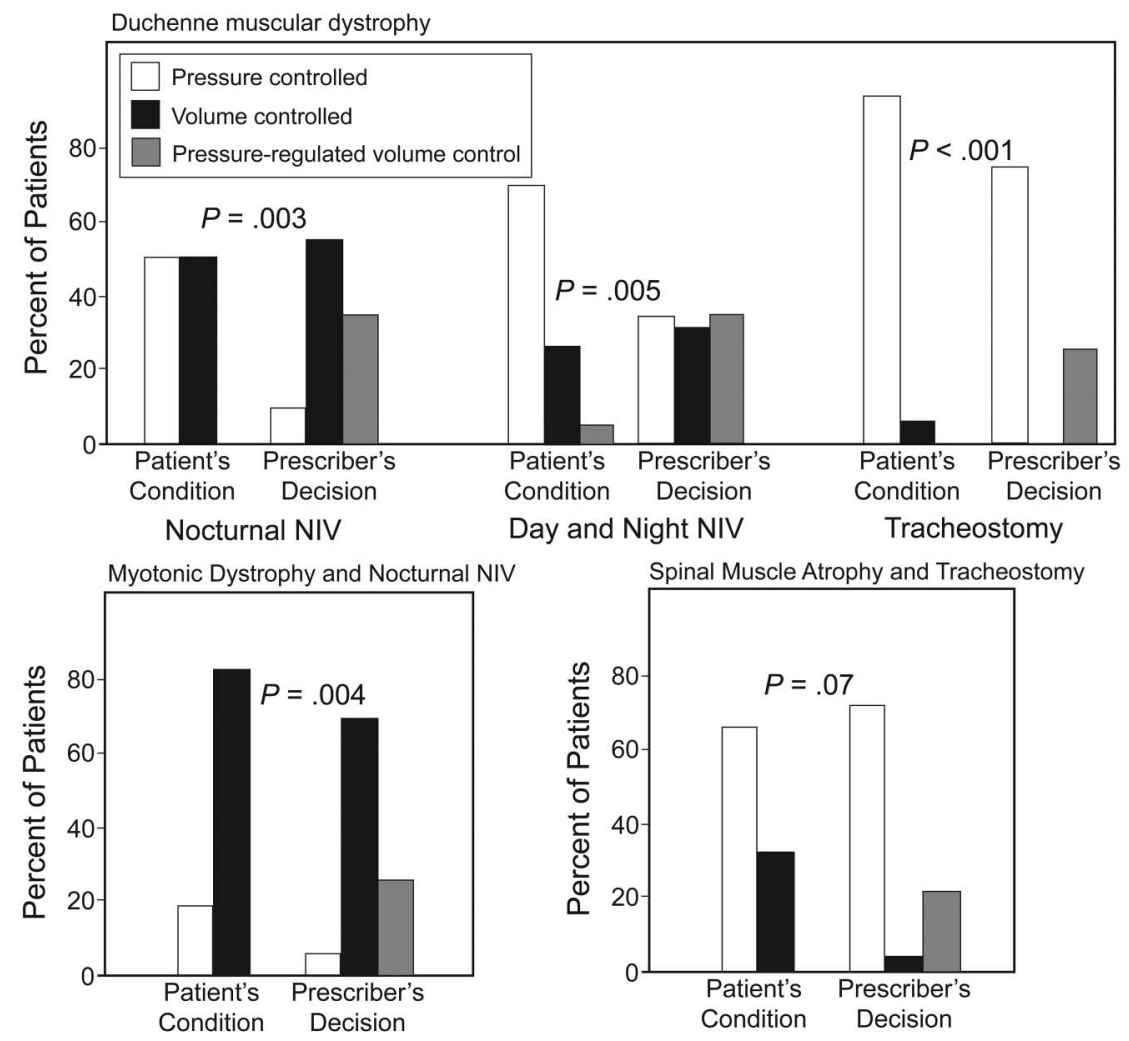

Fig. 3. Ventilation modes used by the patients versus prescriber opinions, according to ventilation interface, in 3 diagnosis groups (only the most frequent conditions were taken into account): Duchenne muscular dystrophy with nocturnal noninvasive ventilation (NIV), night-andday NIV, or night-and-day ventilation via tracheostomy; myotonic dystrophy with nocturnal NIV; and spinal muscular atrophy with invasive ventilation via tracheostomy. 


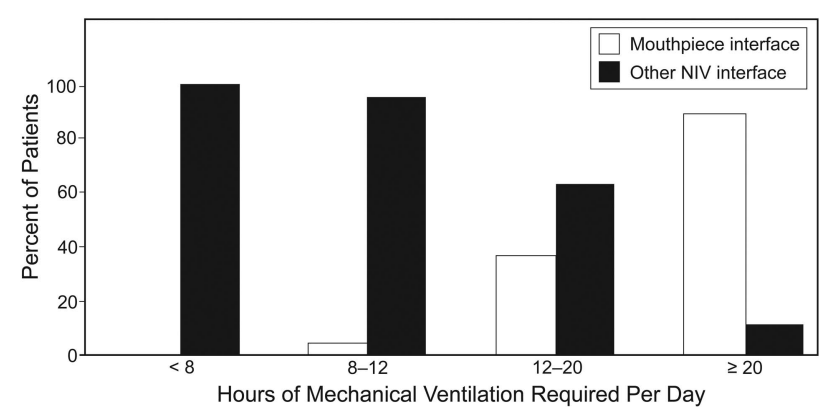

Fig. 4. Percentage of patients who received noninvasive ventilation (NIV) via mouthpiece versus via other NIV interface, according to daily hours of NIV.

creased in those requiring daily MV (Fig. 2). Figure 3 shows the MV modes used versus the prescribers' current MV prescription, according to the patient's diagnosis and the MV interface.

Among the 71 patients using NIV during daytime, 30 used a mouthpiece. The percentage of daytime mouthpiece users increased with the daily duration of ventilation, from no patients using mouthpiece ventilation whose daily NIV use was $<8 \mathrm{~h} / \mathrm{d}$, to $90 \%$ of those who used NIV $\geq 20 \mathrm{~h} / \mathrm{d}$ (Fig. 4).

Table 5 shows the humidification systems used by the patients versus the prescribers' recommended humidification systems. Heated humidifier was the most used and chosen during NIV; however, heat and moisture exchanger (HME) was the most common humidification system used during invasive MV, whereas prescription of filter and heated humidification was comparable in this group.

\section{Discussion}

This study is the first to evaluate and compare prescribers' and patients' expectations regarding long-term MV equipment. Interestingly, the opinions and expectations of the patients and the prescribers differed in many aspects. This survey also compared current MV use in a large group of patients with neuromuscular disease to the prescribers' current MV prescriptions. Because the technology of the ventilators, circuits, and interfaces change continuously, important differences were observed, due to the fact that a patient's MV equipment may reflect a prescription made several years ago.

\section{Knowledge and Patient Comfort}

Only $78 \%$ of the patients were able to correctly describe their MV mode as volume control, pressure control, or a combined mode, and less than of half of the patients were able to describe their MV mode as assisted, controlled, or both. This shows that most patients have a poor knowledge of their MV and of patient-ventilator synchronization. Interestingly, $92 \%$ of the patients who had the possibility to trigger the ventilator insufflations considered that they were able to do it, including all the tracheostomized patients using an assist mode. However, $8 \%$ of the non-tracheostomized patients and $18 \%$ of the tracheostomized patients considered their ventilator trigger insufficiently sensitive. On the other hand, the ventilator trigger was reported as "too sensitive" by $5 \%$ and $3 \%$ of the nontracheostomized and tracheostomized patients, respectively. These results reflect the difficulty of finding a trigger sensitivity that is neither too high nor too low. This is particularly difficult for patients whose inspiratory muscle strength may decrease, which should lead to increasing the trigger sensitivity. An alternative could be the use of a new trigger technology, such as the detection of the inspiratory effort by means of inspiratory muscle electromyography, such as with neutrally adjusted ventilator assistance. ${ }^{6}$ For a home

Table 5. Humidification Systems Used by Patients Versus Humidification Systems Recommended by Prescribers

\begin{tabular}{|c|c|c|c|}
\hline & $\begin{array}{l}\text { Nighttime } \\
\text { NIV }\end{array}$ & $\begin{array}{l}\text { Night-and-Day } \\
\text { NIV }\end{array}$ & $\begin{array}{l}\text { Invasive MV via } \\
\text { Tracheostomy }\end{array}$ \\
\hline Humidification systems used by the patients & $(n=71)$ & $(n=71)$ & $(n=67)$ \\
\hline Heat and moisture exchanger & 9 & 7 & 34 \\
\hline Non-heated humidifier & 11 & 8 & 6 \\
\hline Heated humidifier & 21 & 16 & 20 \\
\hline No humidification system & 30 & 40 & 7 \\
\hline \multicolumn{4}{|l|}{$\begin{array}{l}\text { Humidification systems recommended by the } \\
\text { prescribers, }(n=45)^{*}\end{array}$} \\
\hline Heat and moisture exchanger & 16 & & 27 \\
\hline Non-heated humidifier & 4 & & 5 \\
\hline Heated humidifier & 38 & & 32 \\
\hline No humidification system & 4 & & 0 \\
\hline
\end{tabular}


ventilator such a trigger would require an implantable device for monitoring inspiratory muscle electromyography. When we asked the patients if they would accept a minor surgical procedure to improve their ventilator synchrony, the majority refused, and only $11 \%$ were immediately favorable. Similarly, the majority of the prescribers were not enthusiastic with regard to this possible breakthrough.

\section{Comparison of Patients' and Prescribers' Opinions}

Both the patients and prescribers attached considerable importance to patient/ventilator synchrony, patient respiratory comfort during $\mathrm{MV}$, and the option of built-in patient-controlled cough support. However, the demand for these characteristics and options was generally stronger among the prescribers than among the patients.

Cough support by air-stacking, which does not require any modification of a volumetric ventilator, and intermittent inspiratory pressure may be easily integrated into conventional home ventilators. In contrast, percussive and cough-assist methods require additional technology that may increase ventilator weight and size. A review of the literature ${ }^{7}$ suggests that mechanical insufflationexsufflation can increase the inspired volume at least as well as the other inflation methods, and peak cough flow is as fast as or faster than manual assisted cough associated to an inflation method, and patients seem to prefer mechanical insufflation-exsufflation to the other assistedcough methods. Finally, the insufflation-exsufflation method seems to be at least among the best methods for improving airway clearance. A cheap alternative technique could be to use the ventilator to increase the inspired volume associated with manual assisted cough, if ventilator manufacturers can integrate an intermittent inspiratory pressure mode. The possibility of built-in patient-controlled cough support was considered important by both the patients and prescribers, but the prescribers ranked it higher than did the patient.

The majority of our patients had no preference for any of the different assisted-cough methods, which may be explained by a lack of knowledge and experience. Curiously, among the patients who preferred a technique, they preferred insufflation-exsufflation, followed by intermittent inspiratory pressure and the percussive device, whereas an intermittent inspiratory pressure device was the most frequent cough support device used by the patients, followed by insufflation-exsufflation and the percussive device. This paradox may be explained by the influence of the prescribers, of whom two thirds preferred insufflationexsufflation, in agreement with the literature. ${ }^{7}$ Therefore we expect that the number of patients using insufflationexsufflation will increase in the near future.

\section{Evaluation of the Patients' Equipment Versus the Prescribers' Current Choices}

The choice of the MV mode according to the daily duration of MV is one of the most striking observations of this survey. Indeed, a pressure control mode, mostly delivered by a bi-level pressure device or a pressure support device, was preferentially used in patients needing only nocturnal MV, because these modes are more comfortable than volume control modes during non-leak conditions. ${ }^{8}$ Most clinicians prescribe pressure control modes during sleep, as they allow adjustment of inspiratory time, leak compensation, and improved patient comfort. However, a volume control mode predominated in the patients who also needed daytime MV, mainly via mouthpiece. Although pressure control mode may be used with a mouthpiece, volume control ventilators have better performance for mouthpiece ventilation. ${ }^{9}$ Furthermore, mouthpiece ventilation allows the patient to disconnect him or herself from the ventilator, ideally during expiration, for example to allow speech after each insufflation. Pressure control ventilators, in contrast, respond to disconnection by activating the turbine, to attempt to maintain the targeted positive pressure level. In addition, by definition, pressure control modes are not able to generate the high pressures necessary for effective breath-stacking or lung-volume recruitment. ${ }^{9}, 10$ In contrast, volume control ventilators are able to provide both the tidal volume for sustained ventilation and the pressure and volume required for effective lung-volume recruitment and achievement of a maximal insufflation capacity. ${ }^{9,10}$ Nevertheless, another option for improving cough could be an independent cough-assist device. A second option could be to integrate an additional intermittent-positive-pressure mode (see below) into the ventilator.

When we compared the MV modes used by the patients to the current prescriber prescriptions, we observed that PRVC mode was gaining popularity over volume control mode. PRVC ventilation is a new mode that combines volume control and pressure control with an algorithm that estimates the patient's tidal volume over several breaths, enabling the calculation of the pressure change necessary to achieve the target tidal volume. PRVC is designed to adapt the amount of pressure to changes in respiratory impedance. However, theoretically, PRVC ventilation is not able to cope with unintentional leaks, especially when these leaks vary over time, ${ }^{11}$ as with NIV via mouthpiece or ventilation via uncuffed tracheostomy tube. When unintentional leaks occur during pressure control ventilation, the inspiratory flow delivered by the ventilator increases to reach the target inspiratory airway pressure, whereas the tidal volume decreases. ${ }^{12}$ Carlucci et al ${ }^{13}$ recently observed that, depending on the circuit configuration, many MV devices recognize the delivered volume as the tidal vol- 
ume. Therefore the inspiratory pressure adjustment may paradoxically decrease to a lower level during unintentional leak, which worsens the decrease in tidal volume. In contrast, when the tidal volume is estimated by the expired volume, the tidal volume can be overestimated. ${ }^{14,15} \mathrm{Fi}$ nally, the majority of the PRVC ventilation devices are currently not reliable during unintentional leak, underlining the need to check these modes during unintentional leak.

The fitting and comfort of noninvasive interfaces are crucial for the effectiveness of NIV during sleep. ${ }^{16}$ All different types of interfaces were used by the patients. However, despite their advantage of a minimal facial contact, which widens the field of vision and allows the use of eyeglasses, few patients used nasal pillows. ${ }^{17}$ Until recently, all nasal pillows available in France had intentional leak and therefore could be used only with bi-level ventilators, given that any modification of a medical device (eg, sealing a hole) was prohibited by French law. We encourage manufacturers to develop non-leak nasal pillows, which may be an alternative to mouthpiece MV during daytime. ${ }^{18}$ Another solution to reduce the risk of skin damage is to alternate various types of interfaces. If most prescribers are in favor of this solution, it is not the case for the patients.

As reported in the literature, ${ }^{17} \mathrm{HME}$ was the most commonly used humidification system among the tracheostomized patients, whereas a heated humidification was the most commonly used among the NIV patients. Humidification and warming of the inspired gas may be used to prevent the adverse effects of cool, dry gases on the airway epithelium. The major cause of humidity loss is a unidirectional flow from the ventilator circuit to the patient because of mouth leaks during nasal NIV, and between the tracheal tube and the trachea when using an uncuffed tube during invasive MV. These leaks are extremely common in neuromuscular patients. ${ }^{19,20}$ Therefore, although an HME and a heated humidifier showed similar tolerance and side effects during long-term $\mathrm{MV},{ }^{21}$ we prefer a heated humidifier because of its greater efficacy in case of unintentional leak. ${ }^{22-24}$ In addition, as compared to a heated humidifier, an HME increases the resistance of the circuit and the dead space, and therefore the work of breathing, during invasive MV. ${ }^{25,26}$ However, a tracheostomized patient using a wheelchair represents an exception. In that situation a water tank humidifier built into the circuit and located behind the patient, and often above the tracheostomy tube, exposes the patient to a risk of water inhalation. An HME, in contrast, is safe.

\section{Conclusions}

This large survey underlines the differences between patients and prescribers concerning long-term MV equip- ment and potential improvements. Prescribers are more enthusiastic and more prone than patients to prescribe new technologies such as emergency interface-release systems, contactor for triggering/stopping insufflations or providing larger inspiratory volume, cough assistance devices, or new technologies that could improve speech. ${ }^{27}$ For some of these new technologies, such as PRVC mode, objective clinical benefit remains unproven. Patients are more reluctant than prescribers to adopt new technologies, and many of them had no opinion on such, which might be explained by lack of information, underlining the need for regular MV updates for patients receiving long-term MV.

\section{ACKNOWLEDGMENTS}

We thank ResMed employees Lucile Blaise, Didier Theret, and Olivier Tessier for participation in the elaboration of the questionnaires, and ResMed employees Guillaume Minaret, Vincent Pubill, Louis-Luc Bernard, Bruno Sicre, Philippe Draicchio, Cédric Laillier, and André Bardon for collecting the questionnaires. We thank Isabelle Vaugier for her assistance with the statistical analysis. In addition to the authors, the partners of the Association Française Contre les Myopathies who belong to the research group for improving the match between ventilator technology and neuromuscular patient needs are Frédéric Barbot, Marjorie Figère, Didier Guillemot, Michelle Lejaille, Mourad Machou, Bruno Louis, Lionel Dizet, Pierre Kieny, Alexandra Binoche, Alain Durocher, Maud Lacour, Francis Leclerc, Anne Mallart, Régis Matran, Thierry Perez, Benoit Wallaert, Brigitte Chabrol, Armelle Finet Monnier, Jean Pouget, Emmanuelle Salort Campana, Philippe Soudon, Annie Leroy, Claude Denuelle, Charles Hugo Marquette, and Cécile Pereira. Participating members of l'Association Grenobloise Pour les Insuffisants Respiratoires were Sandra Journet and Daniel Zerillo. Participating members of Service de Réanimation Médicale et d'Assistance Respiratoire, Centre Hospitalier Universitaire du Nord were Bruno Massenavette and Thierry Petitjean.

\section{REFERENCES}

1. Ambrosino N, Carpene N, Gherardi M. Chronic respiratory care for neuromuscular diseases in adults. Eur Respir J 2009;34(2):444-451.

2. Schonhofer B, Sortor-Leger S. Equipment needs for noninvasive mechanical ventilation. Eur Respir J 2002;20(4):1029-1036.

3. Criner GJ, Brennan K, Travaline JM, Kreimer D. Efficacy and compliance with noninvasive positive pressure ventilation in patients with chronic respiratory failure. Chest 1999;116(3):667-675.

4. Lloyd-Owen SJ, Donaldson GC, Ambrosino N, Escarabill J, Farre R, Fauroux B, et al. Patterns of home mechanical ventilation use in Europe: results from the Eurovent survey. Eur Respir J 2005;25(6): 1025-1031.

5. Epstein SK, Singh N. Respiratory acidosis. Respir Care 2001;46(4): 366-383.

6. Terzi N, Pelieu I, Guittet L, Ramakers M, Seguin A, Daubin C, et al. Neurally adjusted ventilatory assist in patients recovering spontaneous breathing after acute respiratory distress syndrome: physiological evaluation. Crit Care Med 2010;38(9):1830-1837.

7. Haas CF, Loik PS, Gay SE. Airway clearance applications in the elderly and in patients with neurologic or neuromuscular compromise. Respir Care 2007;52(10):1362-1381.

8. Betensley AD, Khalid I, Crawford J, Pensler RA, DiGiovine B. Patient comfort during pressure support and volume controlledcontinuous mandatory ventilation. Respir Care 2008;53(7):897-902. 


\section{Long-Term Mechanical Ventilation Equipment for Neuromuscular Patients}

9. Hess DR. Noninvasive ventilation in neuromuscular disease: equipment and application. Respir Care 2006;51(8):896-911; discussion 911-912.

10. Kang SW, Bach JR. Maximum insufflation capacity: vital capacity and cough flows in neuromuscular disease. Am J Phys Med Rehabil 2000;79(3):222-227.

11. Fauroux B, Leroux K, Pepin JL, Lofaso F, Louis B. Are home ventilators able to guarantee a minimal tidal volume? Intensive Care Med 2010;36(6):1008-1014.

12. Storre JH, Bohm P, Dreher M, Windisch W. Clinical impact of leak compensation during non-invasive ventilation. Respir Med 2009; 103(10):1477-1483.

13. Carlucci A, Schreiber A, Mattei A, Malovini A, Bellinati J, Ceriana $\mathrm{P}$, et al. The configuration of bi-level ventilator circuits may affect compensation for non-intentional leaks during volume-targeted ventilation. Intensive Care Med 2013;39(1):59-65.

14. Andrieu MC, Quentin C, Orlikowski D, Desmarais G, Isabey D, Louis B, et al. Inductive plethysmography to control volume-targeted ventilation for leak compensation. Intensive Care Med 2008;34(6): 1150-1155.

15. Khirani S, Louis B, Leroux K, Delord V, Fauroux B, Lofaso F. Harms of unintentional leaks during volume targeted pressure support ventilation. Respir Med 2013;107(7):1021-1019.

16. Elliott MW. The interface: crucial for successful noninvasive ventilation. Eur Respir J 2004;23(1):7-8.

17. Nava S, Navalesi P, Gregoretti C. Interfaces and humidification for noninvasive mechanical ventilation. Respir Care 2009;54(1):71-84.

18. Ishikawa $Y$, Miura $T$, Aoyagi $T$, Ogata $H$, Hamada S, Minami R. Duchenne muscular dystrophy: survival by cardio-respiratory interventions. Neuromusc Disord 2011;21(1):47-51.

19. Gonzalez J, Sharshar T, Hart N, Chadda K, Raphael JC, Lofaso F. Air leaks during mechanical ventilation as a cause of persistent hy- percapnia in neuromuscular disorders. Intensive Care Med 2003; 29(4):596-602.

20. Nardi J, Prigent H, Garnier B, Lebargy F, Quera-Salva MA, Orlikowski D, et al. Efficiency of invasive mechanical ventilation during sleep in Duchenne muscular dystrophy. Sleep Med 2012;13(8): 1056-1065.

21. Nava S, Cirio S, Fanfulla F, Carlucci A, Navarra A, Negri A, et al. Comparison of two humidification systems for long-term noninvasive mechanical ventilation. Eur Respir J 2008;32(2):460-464.

22. Richards GN, Cistulli PA, Ungar RG, Berthon-Jones M, Sullivan CE. Mouth leak with nasal continuous positive airway pressure increases nasal airway resistance. Am J Respir Crit Care Med 1996; 154(1):182-186.

23. Randerath WJ, Meier J, Genger H, Domanski U, Ruhle KH. Efficiency of cold passover and heated humidification under continuous positive airway pressure. Eur Respir J 2002;20(1):183-186.

24. Holland AE, Denehy L, Buchan CA, Wilson JW. Efficacy of a heated passover humidifier during noninvasive ventilation: a bench study. Respir Care 2007;52(1):38-44.

25. Lellouche F, Pignataro C, Maggiore SM, Girou E, Deye N, Taillé S, et al. Short-term effects of humidification devices on respiratory pattern and arterial blood gases during noninvasive ventilation. Respir Care 2012;57(11):1879-1886.

26. Jaber S, Chanques G, Matecki S, Ramonatxo M, Souche B, Perrigault PF, et al. Comparison of the effects of heat and moisture exchangers and heated humidifiers on ventilation and gas exchange during non-invasive ventilation. Intensive Care Med 2002;28(11): 1590-1594.

27. Garguilo M, Leroux K, Lejaille M, Pascal S, Orlikowski D, Lofaso $F$, et al. Patient-controlled PEEP with neuromuscular disease: effect on speech in patients with tracheostomy and mechanical ventilation support. Chest 2013;143(5):1254-1251. 